\title{
Thidiazuron, a phenyl-urea cytokinin, inhibits ergosterol synthesis and attenuates biofilm formation of Candida albicans
}

\author{
Harikrishnan Pandurangan \\ Pondicherry Centre for Biological Science and Educational trust \\ Balamani Arayambath \\ Mahatma Gandhi Postgraduate Institute of Dental Sciences \\ Vijay Karthik Jayaraman \\ Dencity Dental Clinic \\ Kanimozhi Ekambaram \\ Endodontic Clinic \\ Emad A Ahmed \\ King Faisal University \\ Palanisamy Senthilkumar \\ SRM Institute of Science and Technology \\ Hairul-Islam Mohamed Ibrahim \\ King Faisal University \\ Krishnaraj Thirugnanasambantham ( $\sim$ pcbsresearch@gmail.com) \\ Pondicherry Centre for Biological Sciences and Educaional Trust https://orcid.org/0000-0002-5340-8806
}

\section{Research Article}

Keywords: Candida albicans, Thidiazuron, CYP51, docking, ergosterol, biofilm, gene expression

Posted Date: August 6th, 2021

DOI: https://doi.org/10.21203/rs.3.rs-780442/v1

License: @ (1) This work is licensed under a Creative Commons Attribution 4.0 International License. Read Full License 


\section{Abstract}

Candida albicans is a commensal human fungal pathogen that colonizes and develops dental biofilm which cause Oral candidiosis. This study investigates the effects of a new molecule Thidiazuron against the growth and biofilm formation properties of $C$. albicans. This study applied computational and in vitro approaches such as broth microdilution, SEM, time-kill dynamics, crystal violet assay, XTT reduction assay, ergosterol quantification and quantitative RT PCR analysis of gene expression to validate the growth and biofilm inhibitory potential of thidiazuron against $C$. albicans. Preliminary molecular docking study revealed potential interaction between thidiazuron and amino acids residues of CYP51. Further in vitro anti-fungal susceptibility test, SEM and time kill analysis revealed antifungal potency of thidiazuron in dose and time dependent passion. Crystal violet staining, XTT reduction assay and Acridine Orange staining visually confirmed biofilm inhibitory potential of thidiazuron. Gene expression study shows that thidiazuron treatment down regulated the expression of genes involved in ergosterol synthesis, cell adhesion and hyphae development in $C$. albicans. This study identified thidiazuron as CYP51 inhibitor and a new antibiofilm agent against $C$. albicans.

\section{Introduction}

Fungal infections are increasing nowadays due to changes in lifestyle, pollution and increased systemic risk factors like diabetes, autoimmune diseases and immune-suppressant drugs etc. Many fungi are part of biofilm in human muco-dermal infections and on the biomaterials used inside the body. Varieties of anti-fungal agents are available and still drug resistance is often encountered. Conventional antibiotic therapy that leads to antimicrobial resistance is frequently responsible for biofilm-associated infections. So, there is a need for search of new biomolecules exhibiting good anti-fungal activity. One of the commonest opportunistic fungal infections in human and more so in the oral cavity is Candida species and prevention of its biofilm and recurrence is vital in the treatment of Candidiasis. Candida albicans is a fungus that is a major source of device-associated infection due to its potential biofilm formation trait.

Biofilm is a community of microbes produced by the extracellular polymeric factors [1]. It has two main components such as water and densely packed cells. Biofilm formation is a complex process to convert planktonic to sessile mode of cell growth [2]. They are potential for the establishment of infections and forms biological layering in medical devices such as catheter, suction tubes, prosthetic tubes etc., and it also forms reflux process during drug resistance [3,4]. C.albicans biofilm leads to superficial and systematic infections in the human host and it occur frequently in the mucosa or endothelial tissues [1]. In C.albicans, the Extracellular polymeric substances which develop the pathogenic infections and multidrug resistance, has four stages such as adherences, proliferation, maturation and dispersion [5-7]. Various antibiofilm studies reported that Inhibition of biofilm formation in C.albicans by chemically synthesized azole molecules and natural plant molecules pretending the toxics and non-target effects. The search of new biomolecules against antibiofilm activity will improve the management of fungal disease [8-10]. Already few biomolecules were described against the C.albicans biofilms, such as trans-resveratrol, terpenes, catechins, stilbenes, quercetin, tannins, anthocyanins, catechins etc., which inhibits the growth of Extracellular matrix formation and reduced toxicity [10].

Ergosterol is a fungal cell membrane component, which regulates the membrane structure fluidity, permeability, mobility and it stabilizes the membrane structure binding through phospholipids [11]. It also functions as a fungal hormone which stimulates the growth and plays an essential role in oxidative stress during fungi maturation [9]. The alteration in ergosterol biosynthesis revealed that modification of cell membrane fluidity and progression of drug efflux mechanisms leads to release of electrolytes from the endogenous cell membrane [12]. Taken together, these modifications depolarized the mitochondrial membrane potential activity and leads to ROS production [8]. Lipid peroxidation activity was increased by mitochondrial stress that regulates the reciprocal formation of biofilm and cell membrane structural modifications in C.albicans [9]. Ergosterol biosynthesis pathway is governed by expression pattern of different ERG genes (ERG1, ERG3, $E R G 7, E R G 9, E R G 11$ and ERG25), whose products are involved and helps in the synthesis of biofilms in C.albicans [13]. Among ERG genes, ERG11 gene encoding CYP51 enzyme plays a major role in Ergosterol synthesis [14]. [15]. It was also reported that the levels of total ergosterol were significantly lower at later stages of biofilm formation than planktonic cells. But, it was noticed that fluconazole decreased the expression of ERG11 gene in fluconazole sensitive C.albicans biofilm, whereas it increased expression of ERG11 gene in fluconazoleresistant C.albicans biofilm[13].

Based on the earlier reports it is hypothesized that maturation of biofilm in fluconazole-resistant C.albicans was associated with increased ERG11 expression and subsequent Ergosterol synthesis. Thus screening of CYP51 inhibitor could be highly helpful for controling of Candida infections and biofilm associated with artificial implanted medical devices. Thus, new molecules which can inhibit CYP51 will be of potential benefit in the treatment of candidiosis. Hence, in this present study, TDZ (thidiazuron) were docked against ergosterol biosynthesis enzyme (CYP51) and its invitro analysis was done by quantifying total sterol, biofilm fluorescent staining and mRNA quantification of biofilm responsive genes in C.albicans. 


\section{Materials And Methods}

\section{Preparation of protein, ligand and molecular docking study:}

The 3D structure X-ray crystallographic structures of sterol 14-alpha demethylase enzyme (CYP51, PDB code: 5TZ1) was retrieved from RCSB database [16]. The structure of thidiazuron (PubChem CID: 40087) used in this study was retrieved from pubchem database (https://pubchem.ncbi.nlm.nih.gov/compound/) as .sdf format and latter converted to .pdb format using PyMOL software. Docking calculations were executed using AutoDock (version 1.5.2 revision 2) as described in the literature [17,18]. The docked conformations of each ligand were ranked into clusters based on the binding energy and the top ranked conformations were visually analyzed with pymol.

\section{Chemicals, microbial strains and culture conditions:}

C. albicans strain MTCC 183 obtained from Institute of Microbial Technology, Chandigarh, India were cultured in Sabouraud dextrose broth ( $1 \%$ yeast extract, $1 \%$ peptone, $4 \%$ glucose, $1 \%$ agar) and maintained at $4{ }^{\circ} \mathrm{C}$. Standard cell suspensions were prepared by inoculating single colony of $C$. albicans in Tryptone Soya Broth (TSB) (Himedia) medium containing $1 \%$ of glucose and overnight incubation at $37^{\circ} \mathrm{C}$ at $200 \mathrm{rpm}$ in a shaker. Thidiazuron (TDZ) extrapure, 97\% was purchased from Sisco Research Laboratories Pvt. Ltd.(SRL), India. Unless indicated all chemicals and media used in the present study were purchase from Himedia (Mumbai, India).

\section{Antifungal Activity of Thidiazuron:}

Overnight grown fungal cells were collected by centrifugation, subsequently washed in PBS and resuspended to $1 \times 10^{6}$ CFU per milliliter using TSB medium with $1 \%$ glucose. Antifungal activity of thidiazuron $(200$ to $25 \mu \mathrm{M})$ and fluconazole $(25 \mu \mathrm{g})$ were screened using disk diffusion method in Mueller-Hinton agar. In brief, Mueller-Hinton agar was spread with $C$. albicans $\left(1 \times 10^{6} \mathrm{CFU} / \mathrm{ml}\right)$, disk containing test antifungal agent was placed and subsequently incubated for 24 to 48 hours at $37^{\circ} \mathrm{C}$. The results were interpreted based on the measurement of diameter of the zone of inhibition.

\section{Planktonic minimal inhibitory concentration (PMIC)}

The minimal inhibitory concentration (MIC) values of planktonic suspending cells for $C$. albicans was determined in microtitre plates by broth micro-dilution according to the Clinical and Laboratory Standards Institute guidelines, document M27-S4 (CLSI 2012)[19]. Plates were prepared under aseptic conditions. To each well, $100 \mu \mathrm{L}$ of thidiazuron $(200 \mu \mathrm{M})$ and fluconazole $\left(100 \mu \mathrm{g} \mathrm{ml}^{-1}\right)$ in $10 \%(\mathrm{v} / \mathrm{v}) \mathrm{DMSO}$ or sterile water was pipetted into the first row of the plate and serially diluted. Finally, $10 \mu \mathrm{L}$ of fungal suspension $\left(1 \times 10^{6} \mathrm{cfu} / \mathrm{mL}\right) \mathrm{was}$ added to each well and incubated for $24 \mathrm{~h}$ at $37^{\circ} \mathrm{C}$. After incubation $30 \mu \mathrm{l}$ of resarzurin $(0.015 \%)$ was added to each well and further incubated for 2-4 $\mathrm{h}$ for the observation of color change [20]. Plate absorbance was then read at $570 \mathrm{~nm}$ and concentration of thidiazuron/fluconazole that inhibited $50 \%$ of cell growth was defined as PMIC.

\section{Scanning electron microscopy (SEM) analysis}

Planktonic cells of $C$. albicans $\left(1 \times 10^{6} \mathrm{CFU} / \mathrm{mL}\right)$ were prepared $2 \mathrm{~mL}$ of SDB broth, to which thidiazuron and fluconazole at $1 \mathrm{X}$ PMIC ${ }_{50}$ was treated and incubated for $24 \mathrm{~h}$ at $37^{\circ} \mathrm{C}$. Imediately after incubation, the cells were harvested by centrifugation and washed twice with sterile PBS. Immediately, the samples were dehydrated for 5 minutes with series of increasing concentration of ethanol $(50,70,90$, and twice at $100 \%$ ). The dehydrated samples were placed overnight in a vacuum oven at $25^{\circ} \mathrm{C}$, then sputter-coated with gold, and imaged using JEOL Hi-Resolution Scanning Electron Microscope (HRSEM) (Thermoscientific Apreo S, Netherlands).

\section{Time-Kill Assay for $C$. albicans towards Thidiazuron}

The time kill assay of $C$. albicans towards thidiazuron was performed as described earlier[21]. A cell suspension of $C$. albicans $\left(1 \times 10^{6}\right.$ $\mathrm{CFU} / \mathrm{mL})$ was prepared in tubes containing $8 \mathrm{~mL}$ of SDB broth, to which different MIC folds of thidiazuron $(0.5,1,2,4$ and $8 \mathrm{X})$ were added 
and appropriate controls were maintained. All tubes were incubated in a shaking incubator at $37^{\circ} \mathrm{C}$ for $24 \mathrm{~h}$. fungal cell suspensions ( $\left.1 \mathrm{ml}\right)$ were collected at time intervals of $0,6,12,24$, and $48 \mathrm{~h}$, serially diluted in SDA broth, and then plated out on SDA agar. After incubation for $24 \mathrm{~h}$ at $37^{\circ} \mathrm{C}$, colony-forming units (CFU) were counted for individual samples and analyzed.

\section{Inhibitory potential of Thidiazuron against $C$. albicans biofilm}

The $C$. albicans biofilm was measured by crystal violet staining and XTT assay. In brief, the cells suspension of $C$. albicans was determined using a haemocytometer Neubauer improved chamber and adjusted to 1 X 106 CFU/ml in RPMI 1640 medium supplemented with $2 \%(\mathrm{w} / \mathrm{v})$ glucose. To a 96 well flat bottom cell culture plate $200 \mu \mathrm{l}$ of cell suspension along with various concentration of thidiazuron $(100$ to $6.25 \mu \mathrm{M})$ in RPMI medium was co-incubated for $48 \mathrm{~h}$ at $37^{\circ} \mathrm{C}$. Appropriate media and culture controls were also maintained in parallel to the thidiazuron treatment. Then, the supernatant along with suspended planktonic cells were removed and the biofilm was washed twice with sterile PBS. Subsequently, the biofilm in each well was stained with freshly-prepared crystal violet solution $(100 \mu \mathrm{L}$, $0.1 \%, \mathrm{w} / \mathrm{v}$ ) and incubated for $10 \mathrm{mins}$. Then, the unbound stains were removed and the wells were washed with sterile distilled water. Plates were then rocked in $95 \%$ ethanol at room temperature for 30 mins and absorbance recorded at the wavelength of $595 \mathrm{~nm}[18]$.

For XTT assay, the supernatant containing unbound cells and media components was removed from each well, washed twice using sterile PBS wash and $100 \mu \mathrm{l}$ of fresh/sterile medium was added to each well. The PMS (Phenazine methosulfate) solution was prepared by dissolving $3 \mathrm{mg}$ PMS in $1 \mathrm{ml}$ 1X PBS. The XTT solution was prepared by dissolving $4 \mathrm{mg} \mathrm{XTT} \mathrm{in} 4 \mathrm{ml}$ of cell culture medium. Working detection solution was prepared by mixing $10 \mu \mathrm{l}$ of the PMS solution to the $4 \mathrm{ml}$ of XTT solution. Then immediately, $50 \mu \mathrm{l}$ of detection solution made in the previous step was added to each well and incubated for 4 hours at $37^{\circ} \mathrm{C}$. Plates were kept in a shaker for a short period of time (10 seconds) to mix the dye in the solution and absorbance recorded at $450 \mathrm{~nm}$ [22]. The percentage of biofilm inhibition was determined as per earlier an study[23] and 80\% inhibition of biofilm formation was considered as Minimum Biofilm Inhibitory Concentration (MBIC).

\section{Fluorescent microscopic analysis of Biofilm inhibitory activity of Thidiazuron}

C.albicans biofilms were cultured 12 well culture plate with different concentrations of TDZ $(0,6.25,12.5,25,50,100 \mu \mathrm{M})$ in RPMI 1640 medium supplemented with $2 \%(\mathrm{w} / \mathrm{v})$ glucose for $48 \mathrm{~h}$ at $37^{\circ} \mathrm{C}$. The wells were washed trice with sterile Phosphate Buffered Saline (PBS) to remove unbound cells and stained for $30 \mathrm{~min}$ in the dark with Acridine orange. A fluorescent microscope (Optika, Germany) was used to record image stacks in five random locations at 40X magnification. In each experiment, the light intensity, background level, and contrast were maintained at the same level.

\section{Ergosterol Biosynthesis assays:}

The C. albicans cells $\left(1 \times 10^{6} \mathrm{CFU} / \mathrm{ml}\right)$ were inoculated in $50 \mathrm{ml}$ of Sabouraud Dextrose Broth with TDZ $(\mu \mathrm{M})$ or DMSO as the control and incubated for in a shaking incubator at $37^{\circ} \mathrm{C}$ for $18 \mathrm{~h}$. Immediately after incubation, cell biomass centrifuged at $2700 \mathrm{rpm}$ for $5 \mathrm{~min}$, washed and weight of individual pellets were recorded. Then pellet in each tube were treated with $3 \mathrm{ml}$ of alcoholic potassium hydroxide solution (25\%), vortexed for $1 \mathrm{~min}$ and incubated in a water bath at $85^{\circ} \mathrm{C}$ for $60 \mathrm{mins}$. The tubes were then cooled and sterol extraction was conducted via vortexing the samples in water : $n$-heptane mixture (1:3) for $3 \mathrm{~min}$. For analysis, $1 \mathrm{~mL}$ of sterol extracts with five-fold ethanol (100\%) was subjected to scanning between wavelengths of 240 to $300 \mathrm{~nm}$ in UV/VIS Spectrophotometer (LABMAN Scientifics, India). The cells treated with fuconazole and DMSO was considered as fluconazole and negative control respectively. The levels of ergosterol was calculated and expressed as percentage in term of weight of pellet using the below equation:

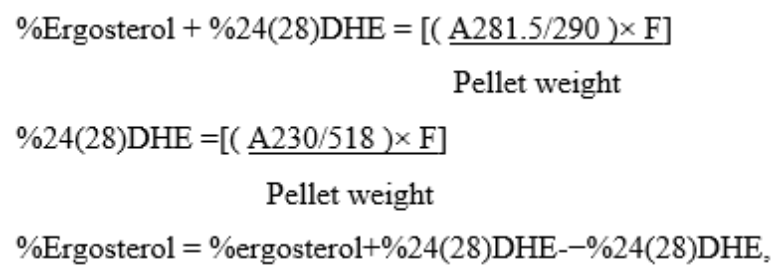


Where, F - factor for dilution in ethanol; 290 - E value (in percentages per centimetre) determined for crystalline ergosterol; 518 - E values (in percentages per centimetre) determined for 24 (28) DHE.

\section{RNA Extraction and qRT-PCR based gene expression analysis of biofilm markers}

C. albicans $\left(1 \times 10^{6} \mathrm{CFU} / \mathrm{ml}\right)$ were cultured in a 12 well culture plate in RPMI 1640 medium supplemented with $2 \%(\mathrm{w} / \mathrm{v})$ glucose and allowed for adhesion. The wells with $2 \mathrm{ml}$ of RPMI 1640 medium containing with TDZ ( $\mu \mathrm{M})$ or DMSO as the control were then incubated statically at $37^{\circ} \mathrm{C}$ for $24 \mathrm{hrs}$. On completion of incubation period, mycelial samples were collected and frozen in liquid $\mathrm{N}_{2}$, and ground into fine powder. Total RNA extraction was performed according to the standard manufacturer's protocol using TRIzol reagent (Ambion, USA). For gene expression analysis, reverse transcription was performed using PrimeScript ${ }^{\text {tM }}$ 1st strand cDNA Synthesis Kit (TAKARA BIO INC, Japan) following the manufacturer's instructions. Reverse transcription (RT) reactions contained $3 \mu \mathrm{g}$ of total RNA samples, $1 \mu \mathrm{L}$ of random Primer $(50 \mu \mathrm{M}), 1 \mu \mathrm{L}$ of dNTP Mixture (10 mM each), $4 \mu \mathrm{L}$ of $5 X$ PrimeScript Buffer, $0.5 \mu \mathrm{L}$ of RNase Inhibitor $(40 \mathrm{U} / \mu \mathrm{l}), 1 \mu \mathrm{l}$ of PrimeScript RTase $(200 \mathrm{U} / \mu \mathrm{l})$ and were topped off to $20 \mu \mathrm{L}$ with DEPC treated water. The thermal profile for RT consisted of incubation at $30^{\circ} \mathrm{C}$ for $10 \mathrm{~min}, 42^{\circ} \mathrm{C}$ for $60 \mathrm{~min}$ and termination of the reaction at $95^{\circ} \mathrm{C}$ at 5 minutes. The quantitative PCR reactions, which were prepared to a final volume of $25 \mu \mathrm{l}$, included $12.5 \mu \mathrm{l}$ of $2 \times$ SYBR® Select Master Mix (Applied Biosystems, USA), $10 \mu \mathrm{mol}$ forward/reverse primers, and one microliter of undiluted cDNA. Primers used in the present study were Table 1[24]. Quantitative RT PCR was performed using a Rotor-Gene Q 2PLEX HRM Real-Time PCR system (Qiagen, Netherlands). The amplification protocol involved enzyme activation at $50^{\circ} \mathrm{C}$ for 2 min, denaturation at $95^{\circ} \mathrm{C}$ for $2 \mathrm{~min}$, followed by 40 cycles at $95^{\circ} \mathrm{C}$ for $15 \mathrm{~s}$ and $60^{\circ} \mathrm{C}$ for $60 \mathrm{~s}$. Three independent experiments were carried out and each cDNA sample was analyzed as triplicate. The average threshold cycle (CT) values were used to calculate relative expression levels normalized to b-tubulin using the $2^{\Delta \Delta C T}$ method (Livak and Schmittgen, 2001).

\section{Statistical analysis}

All experiments were performed in triplicate, and the results are expressed as the mean \pm standard deviation. Statistical analyses of the differences between the means of two experimental groups were evaluated by an unpaired two-tailed Student's t-test using GraphPad Prism 5.0 and a p-value of less than 0.05 was considered significant.

\section{Results}

\section{Computational analysis of CYP51 and thidiazuron interaction:}

Interaction of CYP51 amino acid residues with thidiazuron was studied to get information on the ligand-protein interactions. Molecular docking analysis revealed that thidiazuron has binding potency towards CYP51 with binding energy $-5.86 \Delta \mathrm{G}$ (Table 2). Detailed analysis of the interactions revealed 2 hydrogen bonds, 4 hydrophobic and 2 miscellanous bonds (Fig 1). The Nitrogen and Hydrogen group of $8^{\text {th }}$ carbon from thidiazuron formed two hydrogen bonds with the amino acid residue His377 and Met508 with the distance of

$1.97 \AA$ A each respectively. In addition, two Pi-Alkyl Hydrophobic bond interaction was noticed between thidiazuron and LEU121 and LEU 376 of CYP51 enzyme (Fig 1 and Table 2).

\section{Antifungal activity of thidiazuron:}

Analysis of thidiazuron using disc diffusion method revealed its antifungal potency against C.albicans (Fig 2A). Results from the present study exhibited a thidiazuron mediated dose dependent reduction in C.albican's zone of inhibition (Fig 2B). Also the growth inhibitory potential of thidiazuron at concentration of $100 \mu \mathrm{M}$ was comparable to the positive control, fluconazole. The planktonic minimal inhibitory concentration (PMIC) of thidiazuron and fluconazole that was tested against $C$.albicans was shown in Fig $2 \mathrm{C}$ and D. The PMIC 50 of thidiazuron and fluconazole against C.albicans was noticed to be $41.9 \mu \mathrm{M}$ and $14.21 \mu \mathrm{g} / \mathrm{ml}$ respectively. SEM analysis of thidiazuron treated $C$. albicans further confirmed the antifungal activity of thidiazuron. SEM analysis also revealed that in the control group $C$. albicans were intact, but in both thidiazuron and fluconazole groups, the cells with damaged membranes were noticed (Fig 2E). Further time kill study revealed that the growths of $\mathrm{C}$.albicans cells were inhibited by thidiazuron in a both concentration and time dependent manner (Fig 3). The growth of C.albicans cells that were grown in the presence of $21 \mu \mathrm{M}$ (0.5X PMIC) of thidiazuron were hardly retarded over control (DMSO), whereas higher concentrations (1X to 8X PMIC) drastically reduced the growth of C.albicans cells in time dependent 
manner. At concentrations $1 \mathrm{X}$ to $4 \mathrm{X}$ PMIC, $100 \%$ growth inhibition of C.albicans were achieved at $48 \mathrm{hr}$, whereas for $8 \mathrm{X} 100 \%$ inhibition of C.albicans growth was achieved with $24 \mathrm{hr}$ of treatment as shown in figure 3.

\section{In vitro C. albicans biofilm inhibitory potential of thidiazuron:}

Both Crystal Violet staining method and XTT reduction assay revealed that thidiazuron inhibits C.albicans biofilm formation in dose dependent manner. The crystal violet staining method revealed that thidiazuron displayed C.albicans biofilm inhibition starting from $6 \mu \mathrm{M}$ and $50 / 100 \mu \mathrm{M}$ concentration $100 \%$ inhibition in biofilm formation was noticed (Fig $4 \mathrm{~A}$ ). Similar pattern of biofilm inhibition was also noticed from XTT reduction assay (Fig 4B). In addition the fluorescent microscopic analysis of Acridine Orange stained biofilm visually revealed that thidiazuron inhibited C.albicans biofilm formation in a dose dependent manner (Fig 4C).

\section{Thidiazuron inhibited ergosterol synthesis in C. albicans}

Effect of thidiazuron on ergosterol synthesis in $C$. albicans was analysed by spectrophotometric spectral absorption pattern between 240 and $300 \mathrm{~nm}$. Results from the present study demonstrated ergosterol synthesis inhibitory potential of thidiazuron. Treatment with $0.5 \mathrm{X}$ PMIC thidiazuron reduced $35 \%$ ergosterol content, whereas, the total ergosterol content was decreased to 93 and $100 \%$ respectively in $C$. albicans treated with $1 \mathrm{X}$ and $2 \mathrm{X}$ PMIC thidiazuron (Fig 5).

\section{Thidiazuron modulated gene expression in C. albicans}

Inhibitory effect of thidiazuron on genes involved in $C$. albicans biofilm formation was analysed using quantitative real time PCR (qRT-PCR). Thidiazuron treatment at PMIC $_{50}$ concentration modulated the expression pattern of genes involved in the regulation of adhesion, hyphal growth and ergosterol synthesis. The present study results revealed that thidiazuron significantly down regulated the expression of genes involved in adhesion and hypahae development that includes ALS3, EAP1, EFG1, HWP and SAP5 (Fig 6). Thidiazuron also significantly down regulated the expression of ERG3 and ERG25 that are involved in ergosterol synthesis (Fig 6), whereas, negative transcription regulator of hyphae (NRG1) was significantly up-regulated by thidiazuron treatment as shown in figure 6 . Taken together, thidiazuron mediated inhibition of ERG11 down-regulated other genes involved in ergosterol synthesis and hyphae growth and finally inhibited $C$. albicans biofilm.

\section{Discussion}

Candida albicans is a commensal fungal species that colonies human mucosal surfaces. Increased colonization of $C$. albicans in root carious lesions was reported to promote tooth decay[25]. Emerging antifungal drugs resistance in $C$. albicans has been increasing due to biofilm phenotypes, which makes it vital for identification of new antifungal agents. Earlier studies demonstrated that synthetic plant cytokinin (for chlorfenuron) has potency to inhibit budding yeast cell division in Saccharomyces cerevisiae[26]. Hence in the present study we applied computational and biological approach to validate the antifungal and antibiofilm potential of thidiazuron against $C$. albicans.

Targeting ergosterol biosynthesis has been proven as a strategy to inhibit growth of different Candida spp including $C$. albicans and overcome antifungal drug resistance [27]. Cytochrome P450 enzyme (CYP51) encoded by gene ERG11 is required for biosynthesis of ergosterol and also reported as potential antifungal drug target in the treatment of $C$. albicans[16]. In the present study, amino acid His-377 in K/ $\beta 1-4$ loop and Met-508 in $\beta 4$ hairpin structure of CYP51 are involved in hydrogen bonded interaction with thidiazuron. Similar interactions have been reported between posaconazole or tetrazole-based drug candidate (VT-1161) and CYP51 [16]. Hydrogen bonding plays a significant role in protein binding, thus hydrogen bonding between thidiazuron and 14-alpha demethylase enzyme affects the positioning of the natural ligands, which improves the drug binding potency (Fig 1). Hargrove et al[16] noticed that CYP51 inhibitory potential of tetrazole-based modified drug candidate was enhanced by the $\mathrm{H}$-bond between the imidazole ring of His-377 and candidate drug. The Leucine residues in B-helix were reported to provide higher ability for interaction of C4-monomethyl sterols towards mammalian and fungal CYP51 that plays essential role in binding and metabolism of the sterol substrates[28]. Similarly, two Pi-Alkyl Hydrophobic bond interactions were noticed between thidiazuron and Leucine residues of CYP51. Altogether our computational study revealed that thidiazuron has potency to bind with CYP51 via interaction to its functionally important amino acid residues. 
Current pharmacological treatments against oral candidiasis fail in long-term efficacy against C.albicans. In addition, prevalence of resistance towards antifungal agent in usage has increased and emerged as a main limitation of antibiofilm activity[29]. Results from the present study confirmed antifungal potency of thidiazuron in does dependent manner. In addition, SEM images clearly indicated that thidiazuron affected cell membrane integrity and hypha morphogenesis associated with biofilm formation. In support to our study, SEM observations of eugenol and cinnamaldehyde treatment revealed similar interference in cell membrane integrity in biofilm and planktonic cells of $C$. albicans[30,31].

In C. albicans, yeast-to-hypha morphogenesis is associated with expression of genes encoding several virulence factors which are essential in biofilm formation in oral mucosa and other surfaces that were used in prosthodontics[32]. This study indicated thidiazuron treatment significantly down regulated the expression of genes involved in adhesion and hypahae development that includes $A L S 3$, EAP1, EFG1, HWP and SAP5. The ALS3 and HWP are most highly expressed genes in C. albicans biofilm cells and responsible to the adhesion ability[33]. Since adhesion trait of $C$. albicans is directly associated with the biofilm formation, it is mandatory for a new antibiofilm agent with anti-adhesion[34]. Thus the pattern of thidiazuron in down regulating the expression of ALS3 and HWP clears its potency as a new antibiofilm molecule against $C$. albicans. Attenuating from yeast-to-hyphae morphological transition or/and inhibition of hyphal development were suggested as a potential antifungal therapeutic strategy against $C$. albicans[35]. Down regulation of genes EAP1, EFG1 and $S A P 5$ that are involved in regulation of hyphae development strongly supports antifungal potency of thidiazuron. Expression of gene encoding EFG1 transcriptional activator is critical for yeast-hyphae transition[36]. Thidiazuron mediated down regulation of EFG1 expression is likely responsible for the dramatic decrease in expression its downstream targets genes including ALS3, HWP1 and SAP5[37,38]. Unlike other genes, thidiazuron treatment upregulated the expression of NRG1, which is a hyphae-repressing transcription factor that inhibits filamentous growth and biofilm formation[38].

The biomolecule Thidiazuron was evaluated for anti-fungal activity against $C$. albicans. Molecular docking analysis revealed that thidiazuron has the binding potency towards CYP51 enzyme. Thidiazuron exihibited a dose dependent reduction in the zone of inhibition. C.albican's biofilm inhibition potential was also seen in a dose dependent manner by crystal violet staining and XTT reduction assay. Total ergosterol synthesis could be inhibited by 2 X PMIC thidiazuron. qRT-PCR analysis of Thidiazuron treated C. albican's biofilm showed down-regulation of of the genes involved in hyphae development and significantly up-regulated the negative transcription regulator of hyphae. Based on the findings of this study, we conclude that the biomolecule Thidiazuron is a potential anti-fungal agent which could be evaluated further for clinical applications in the management of various systemic and local $C$. albicans infection.

\section{References}

1. Donlan RM. Biofilms and device-associated infections. Emerg Infect Dis [Internet]. 2001;7:277-81. Available from: http://www.ncbi.nlm.nih.gov/pubmed/11294723

2. Okada M, Sato I, Cho SJ, Iwata H, Nishio T, Dubnau D, et al. Structure of the Bacillus subtilis quorum-sensing peptide pheromone ComX. Nat Chem Biol [Internet]. 2005;1:23-4. Available from: http://www.nature.com/articles/nchembio709z

3. Sims CR, Ostrosky-Zeichner L, Rex JH. Invasive Candidiasis in Immunocompromised Hospitalized Patients. Arch Med Res [Internet]. 2005;36:660-71. Available from: https://linkinghub.elsevier.com/retrieve/pii/S0188440905002389

4. Ganguly S, Mitchell AP. Mucosal biofilms of Candida albicans. Curr Opin Microbiol [Internet]. 2011;14:380-5. Available from: https://linkinghub.elsevier.com/retrieve/pii/S1369527411000816

5. Harikrishnan P, Subha TS, Kavitha V, Gnanamani A. Microbial Adhesion on Orthodontic Ligating Materials: An \&amp;lt;i\&amp;gt;in Vitro\&amp;lt;/i\&amp;gt; Assessment. Adv Microbiol [Internet]. 2013;03:108-14. Available from: http://www.scirp.org/journal/doi.aspx? DOI=10.4236/aim.2013.31017

6. Nett J. The Host's Reply to Candida Biofilm. Pathogens [Internet]. 2016;5:33. Available from: http://www.mdpi.com/2076-0817/5/1/33

7. Lohse MB, Gulati M, Johnson AD, Nobile CJ. Development and regulation of single- and multi-species Candida albicans biofilms. Nat Rev Microbiol [Internet]. 2018;16:19-31. Available from: http://www.nature.com/articles/nrmicro.2017.107

8. Hu L-B, Ban F-F, Li H-B, Qian P-P, Shen Q-S, Zhao Y-Y, et al. Thymol Induces Conidial Apoptosis in Aspergillus flavus via Stimulating K + Eruption. J Agric Food Chem [Internet]. 2018;66:8530-6. Available from: https://pubs.acs.org/doi/10.1021/acs.jafc.8b02117 
9. Khan I, Bahuguna A, Kumar P, Bajpai VK, Kang SC. Antimicrobial Potential of Carvacrol against Uropathogenic Escherichia coli via Membrane Disruption, Depolarization, and Reactive Oxygen Species Generation. Front Microbiol [Internet]. 2017;8. Available from: http://journal.frontiersin.org/article/10.3389/fmicb.2017.02421/full

10. Simonetti G, Palocci C, Valletta A, Kolesova O, Chronopoulou L, Donati L, et al. Anti-Candida Biofilm Activity of Pterostilbene or Crude Extract from Non-Fermented Grape Pomace Entrapped in Biopolymeric Nanoparticles. Molecules [Internet]. 2019;24:2070. Available from: https://www.mdpi.com/1420-3049/24/11/2070

11. Krumpe K, Frumkin I, Herzig Y, Rimon N, Özbalci C, Brügger B, et al. Ergosterol content specifies targeting of tail-anchored proteins to mitochondrial outer membranes. Brodsky JL, editor. Mol Biol Cell [Internet]. 2012;23:3927-35. Available from:

https://www.molbiolcell.org/doi/10.1091/mbc.e11-12-0994

12. Kumari P, Arora N, Chatrath A, Gangwar R, Pruthi V, Poluri KM, et al. Delineating the Biofilm Inhibition Mechanisms of Phenolic and Aldehydic Terpenes against Cryptococcus neoformans. ACS Omega [Internet]. 2019;4:17634-48. Available from:

https://pubs.acs.org/doi/10.1021/acsomega.9b01482

13. Borecká-Melkusová S, Moran GP, Sullivan DJ, Kucharíková S, Chorvát Jr D, Bujdáková H. The expression of genes involved in the ergosterol biosynthesis pathway in Candida albicans and Candida dubliniensis biofilms exposed to fluconazole. Mycoses [Internet]. 2009;52:118-28. Available from: http://doi.wiley.com/10.1111/j.1439-0507.2008.01550.x

14. Morschhäuser J. The genetic basis of fluconazole resistance development in Candida albicans. Biochim Biophys Acta - Mol Basis Dis [Internet]. 2002;1587:240-8. Available from: https://linkinghub.elsevier.com/retrieve/pii/S092544390200087X

15. Mukherjee PK, Chandra J, Kuhn DM, Ghannoum MA. Mechanism of Fluconazole Resistance in Candida albicans Biofilms: PhaseSpecific Role of Efflux Pumps and Membrane Sterols. Infect Immun [Internet]. 2003;71:4333-40. Available from: https://journals.asm.org/doi/10.1128/IAI.71.8.4333-4340.2003

16. Hargrove TY, Friggeri L, Wawrzak Z, Qi A, Hoekstra WJ, Schotzinger RJ, et al. Structural analyses of Candida albicans sterol 14ademethylase complexed with azole drugs address the molecular basis of azole-mediated inhibition of fungal sterol biosynthesis. $J$ Biol Chem. 2017;292:6728-43.

17. Morris GM, Huey R, Lindstrom W, Sanner MF, Belew RK, Goodsell DS, et al. AutoDock4 and AutoDockTools4: Automated docking with selective receptor flexibility. J Comput Chem [Internet]. 2009;30:2785-91. Available from: http://doi.wiley.com/10.1002/jcc.21256

18. Emeka PM, Badger-Emeka LI, Ibrahim HIM, Thirugnanasambantham K, Hussen J. Inhibitory potential of mangiferin on glucansucrase producing streptococcus mutans biofilm in dental plaque. Appl Sci. 2020;10:1-17.

19. Clinical and Laboratory Standards Institute [CLSI]. Reference Method for Broth Dilution Antifungal Susceptibility Testing of Filamentous Fungi; Approved Standard: Document M38-A2. 2nd ed. Wayne, PA: Clinical and Laboratory Standards Institute; 2008.

20. Menon T, Punithavathy P, Nalina K. Antifungal susceptibility testing of Candida tropicalis biofilms against fluconazole using calorimetric indicator resazurin. Indian J Pathol Microbiol [Internet]. 2012;55:72. Available from: http://www.ijpmonline.org/text.asp? 2012/55/1/72/94861

21. Ali I, Khan FG, Suri KA, Gupta BD, Satti NK, Dutt P, et al. In vitro antifungal activity of hydroxychavicol isolated from Piper betle L. Ann Clin Microbiol Antimicrob [Internet]. 2010;9:7. Available from: http://ann-clinmicrob.biomedcentral.com/articles/10.1186/1476-0711-9-7

22. Roehm NW, Rodgers GH, Hatfield SM, Glasebrook AL. An improved colorimetric assay for cell proliferation and viability utilizing the tetrazolium salt XTT. J Immunol Methods [Internet]. 1991;142:257-65. Available from:

https://linkinghub.elsevier.com/retrieve/pii/002217599190114U

23. Subramenium GA, Swetha TK, lyer PM, Balamurugan K, Pandian SK. 5-hydroxymethyl-2-furaldehyde from marine bacterium Bacillus subtilis inhibits biofilm and virulence of Candida albicans. Microbiol Res [Internet]. 2018;207:19-32. Available from:

https://linkinghub.elsevier.com/retrieve/pii/S0944501317304925

24. Theberge S, Semlali A, Alamri A, Leung KP, Rouabhia M. C. albicans growth, transition, biofilm formation, and gene expression modulation by antimicrobial decapeptide KSL-W. BMC Microbiol [Internet]. 2013;13:246. Available from: 
http://bmcmicrobiol.biomedcentral.com/articles/10.1186/1471-2180-13-246

25. Du Q, Ren B, He J, Peng X, Guo Q, Zheng L, et al. Candida albicans promotes tooth decay by inducing oral microbial dysbiosis. ISME J [Internet]. 2021;15:894-908. Available from: http://www.nature.com/articles/s41396-020-00823-8

26. Iwase M, Okada S, Oguchi T, Toh-e A. Forchlorfenuron, a phenylurea cytokinin, disturbs septin organization in Saccharomyces cerevisiae. Genes Genet Syst [Internet]. 2004;79:199-206. Available from: http://www.jstage.jst.go.jp/article/ggs/79/4/79_4_199/_article

27. Onyewu C, Blankenship JR, Del Poeta M, Heitman J. Ergosterol Biosynthesis Inhibitors Become Fungicidal when Combined with Calcineurin Inhibitors against Candida albicans, Candida glabrata , and Candida krusei. Antimicrob Agents Chemother [Internet]. 2003;47:956-64. Available from: https://journals.asm.org/doi/10.1128/AAC.47.3.956-964.2003

28. Lepesheva GI, Zaitseva NG, Nes WD, Zhou W, Arase M, Liu J, et al. CYP51 from Trypanosoma cruzi: A phyla-specific residue in the B' helix defines substrate preferences of sterol 14a-demethylase. J Biol Chem. 2006;281:3577-85.

29. Madariaga-Venegas F, Fernández-Soto R, Duarte LF, Suarez N, Delgadillo D, Jara JA, et al. Characterization of a novel antibiofilm effect of nitric oxide-releasing aspirin (NCX-4040) on Candida albicans isolates from denture stomatitis patients. Bencharit S, editor. PLoS One [Internet]. 2017;12:e0176755. Available from: https://dx.plos.org/10.1371/journal.pone.0176755

30. Bennis S, Chami F, Chami N, Bouchikhi T, Remmal A. Surface alteration of Saccharomyces cerevisiae induced by thymol and eugenol. Lett Appl Microbiol [Internet]. 2004;38:454-8. Available from: https://onlinelibrary.wiley.com/doi/10.1111/j.1472-765X.2004.01511.x

31. Khan MSA, Ahmad I. Antibiofilm activity of certain phytocompounds and their synergy with fluconazole against Candida albicans biofilms. J Antimicrob Chemother [Internet]. 2012;67:618-21. Available from: https://academic.oup.com/jac/articlelookup/doi/10.1093/jac/dkr512

32. Bonilla Rodríguez Y, Moreno Maldonado V, Muñoz Hernández B, Palma Cortés G. In vitro adhesion of Candida albicans in three different tissue conditioners used in prosthodontics. Rev Odontol Mex. 2012;16:40-5.

33. Nobile CJ, Andes DR, Nett JE, Smith FJ, Yue F, Phan Q-T, et al. Critical Role of Bcr1-Dependent Adhesins in C. albicans Biofilm Formation In Vitro and In Vivo. Johnson A, editor. PLoS Pathog [Internet]. 2006;2:e63. Available from:

https://dx.plos.org/10.1371/journal.ppat.0020063

34. Blankenship JR, Mitchell AP. How to build a biofilm: a fungal perspective. Curr Opin Microbiol [Internet]. 2006;9:588-94. Available from: http://www.ncbi.nlm.nih.gov/pubmed/17055772

35. Sionov RV, Feldman M, Smoum R, Mechoulam R, Steinberg D. Anandamide prevents the adhesion of filamentous Candida albicans to cervical epithelial cells. Sci Rep [Internet]. 2020;10:13728. Available from: http://www.ncbi.nlm.nih.gov/pubmed/32792528

36. Ramage G, VandeWalle K, LÃ $\tilde{A}^{3}$ pez-Ribot JL, Wickes BL. The filamentation pathway controlled by the Efg1 regulator protein is required for normal biofilm formation and development in Candida albicans. FEMS Microbiol Lett [Internet]. 2002;214:95-100. Available from: https://academic.oup.com/femsle/article-lookup/doi/10.1111/j.1574-6968.2002.tb11330.x

37. Staib P, Kretschmar M, Nichterlein T, Hof H, Morschhäuser J. Transcriptional Regulators Cph1p and Efg1p Mediate Activation of the Candida albicans Virulence Gene SAP5 during Infection. Infect Immun [Internet]. 2002;70:921-7. Available from:

https://journals.asm.org/doi/10.1128/IAl.70.2.921-927.2002

38. James KM, MacDonald KW, Chanyi RM, Cadieux PA, Burton JP. Inhibition of Candida albicans biofilm formation and modulation of gene expression by probiotic cells and supernatant. J Med Microbiol. 2016;65:328-36.

\section{Declarations}

\section{Acknowledgment:}

The authors are thankful to the Pondicherry Center for Biological Science and Educational Trust (PCBS), Tamil Nadu, India for providing the necessary facility to carry out the work. The authors also acknowledge the SRM Institute of Science and Technology, Tamil Nadu, India for providing access to utilize Scanning Electron Microscopy (SEM). Experimental help by Mr. Premraj, Research Office, PCBS is also gratefully acknowledged 


\section{Statements \& Declarations}

\section{Author contributions:}

$\mathrm{KT}, \mathrm{HP}$, and $\mathrm{HMI}$ designed and conceptualized the experiment. $\mathrm{KT}, \mathrm{BA}, \mathrm{VKJ}, \mathrm{KE}$ and EAA performed computational analysis and drafted the MS. HP, PS and HMI performed invitro biofilm inhibitory and enzymatic studies; $\mathrm{KT}, \mathrm{HMI}, \mathrm{HP}$ and PS involved in sample preparation and SEM analysis; RB, H-GL, JK, and KK revised the first draft of the manuscript including tables and figures. $\mathrm{KT}$ and HMI involved in studies related to gene expression analysis. All authors drafted, contributed and approved the final manuscript.

\section{Funding}

This work was not funded by any external funding agencies

\section{Conflict of Interest / Competing interests}

The authors declare that they have no conflict of interest.

\section{Ethics approval}

This article does not contain any studies with human participants or animals performed by any of the authors

\section{Tables}

Table 1 List of primer sequences for biofilm marker genes used for qRT-PCR.

\begin{tabular}{|c|c|c|c|c|}
\hline Gene & Forward primer & Reverse primer & \begin{tabular}{|l} 
Amplicon \\
size (bp) \\
\end{tabular} & Reference \\
\hline ALS3 & AATGGTCCTTATGAATCACCATCTACTA & GAGTTTTCATCCATACTTGATTTCACAT & 51 & 24 \\
\hline EAP1 & CTGCTCACTCAACTTCAATTGTCG & GAACACATCCACCTTCGGGA & 51 & 24 \\
\hline EFG1 & TATGCCCCAGCAAACAACTG & TTGTTGTCCTGCTGTCTGTC & 202 & 24 \\
\hline NRG1 & CACCTCACTTGCAACCCC & GCCCTGGAGATGGTCTGA & 198 & 24 \\
\hline HWP1 & GCTCAACTTATTGCTATCGCTTATTACA & GACCGTCTACCTGTGGGACAGT & 67 & 24 \\
\hline SAP5 & CAGAATTTCCCGTCGATGAGA & CATTGTGCAAAGTAACTGCAACAG & 78 & 24 \\
\hline ERG3 & TCCAGTTGATGGGTTCTTCCA & GGACAGTGTGACAAGCGGTA & 179 & $\begin{array}{l}\text { This } \\
\text { study }\end{array}$ \\
\hline ERG25 & TGCTGCTCCATTTGGATTGG & GGAATGAGCATCAACGGCTT & 175 & \begin{tabular}{|l|} 
This \\
study
\end{tabular} \\
\hline ACT1 & GCTGGTAGAGACTTGACCAACCA & GACAATTTCTCTTTCAGCACTAGTAGTGA & 87 & 24 \\
\hline
\end{tabular}

ALS3 - Hyphal-specific Cell wall adhesin; EAP1 - hyphae-specific cell wall adhesin protein; EFG1 - hyphae-specific gene activator; NRG1 - transcriptional repressor of hyphae-specific genes; HWP1 - hyphae-specific cell wall protein; SAP5 secreted aspartyl proteases; ERG3 - C-5 sterol desaturase; ERG25 - methylsterol monooxygenase and ACT1 - actin related gene 1

Table 2 Interactions of Thidiazuron and amino acid residues of CYP51 


\begin{tabular}{|c|c|c|c|c|c|c|c|}
\hline Sl.No & Ligand & $\begin{array}{l}\text { Pubchem } \\
\text { ID }\end{array}$ & $\begin{array}{l}\text { Binding } \\
\text { energy }\end{array}$ & $\begin{array}{l}\text { Ligand } \\
\text { efficiency }\end{array}$ & $\begin{array}{l}\text { Intermole } \\
\text { energy }\end{array}$ & Ligand atoms (ring) & $\begin{array}{l}\text { Docked amino } \\
\text { acid residue (bond } \\
\text { length) }\end{array}$ \\
\hline 1. & \begin{tabular}{|l|} 
Thidiazuron \\
\end{tabular} & CID_40087 & -5.86 & -0.39 & -6.27 & $\begin{array}{l}\text { Conventional Hydrogen } \\
\text { Bond: } \\
\text { C8 S-N } \\
\text { C8 N-H } \\
\text { Pi-Alkyl Hydrophobic } \\
\text { bond: } \\
\text { O } \\
\text { O } \\
\text { Pi-Pi T shaped } \\
\text { Hydrophobic bond: } \\
\text { O } \\
\text { O } \\
\text { Miscellanous sulfur } \\
\text { Bond: } \\
\text { C8-S } \\
\text { Miscellanous sulfur } \\
\text { Bond: } \\
\text { C8 S-N }\end{array}$ & 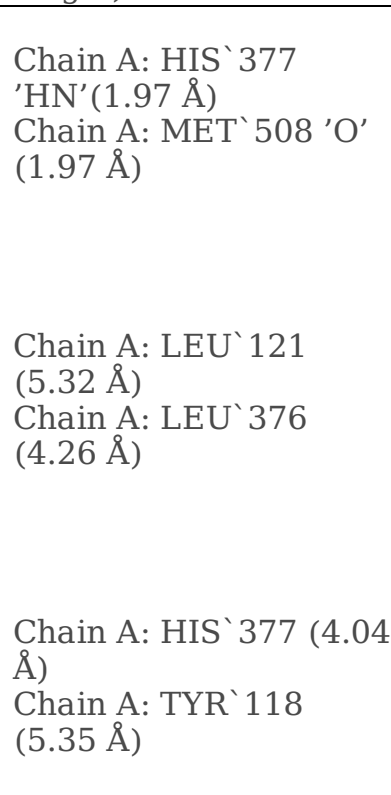 \\
\hline & & & & & & & $\begin{array}{l}\text { Chain A: MET`508 'O' } \\
(2.89 \AA)\end{array}$ \\
\hline & & & & & & & $\begin{array}{l}\text { Chain A: HIS` } 377 \\
\text { 'HN'(2.97 } \AA) \\
\end{array}$ \\
\hline
\end{tabular}

\section{Figures}



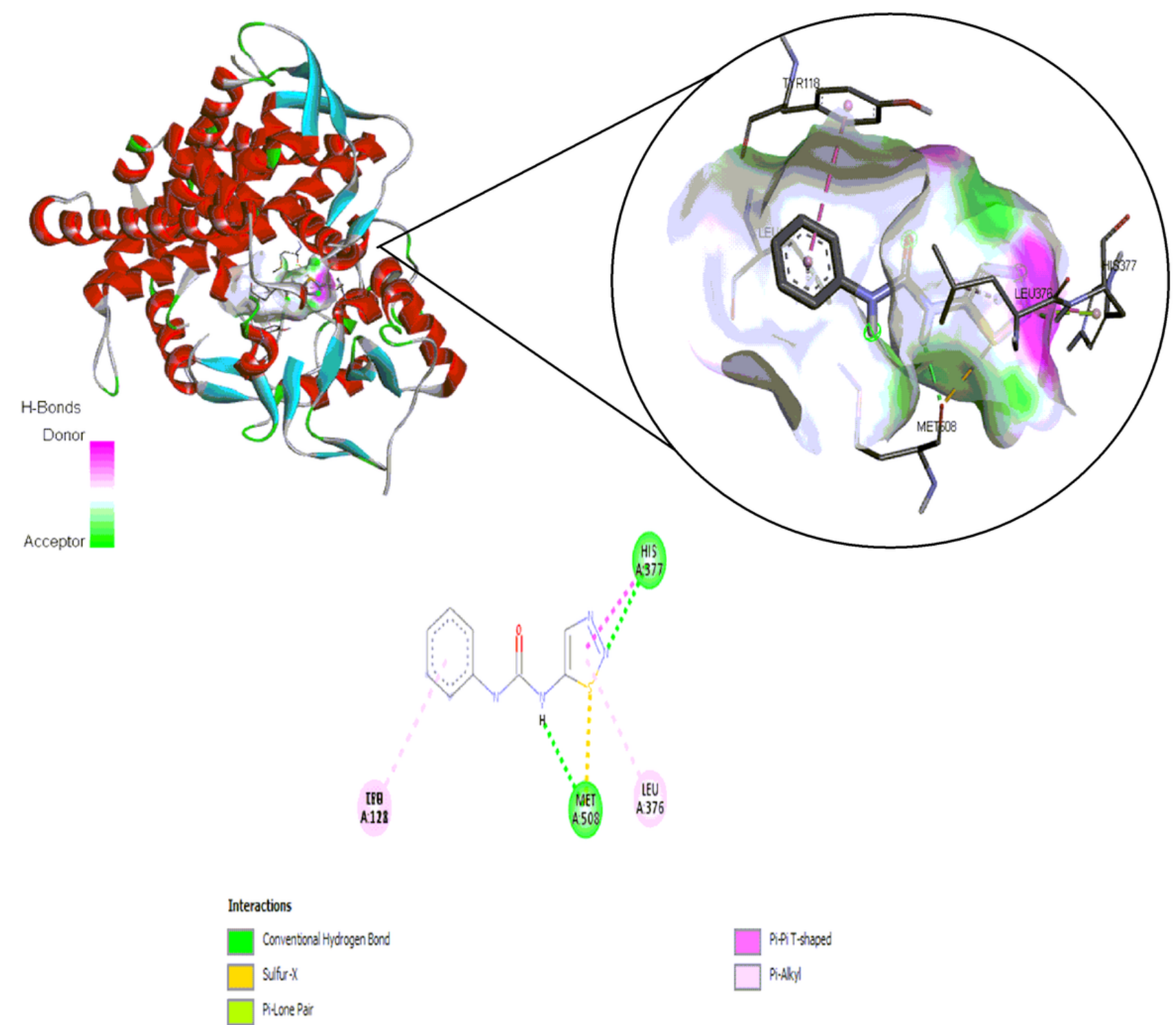

\section{Figure 1}

Interaction of thidiazuron to the active site of C.albicans sterol 14a-demethylase (CYP51). Green colored line shows conventional hydrogen bonded interaction between thidiazuron and His377 and Met508 aminoacids residues of CYP51. Amino acids including Leu121, Leu376 and Tyr118 were involved in hydrophobic interaction with the thidiazuron. 
A

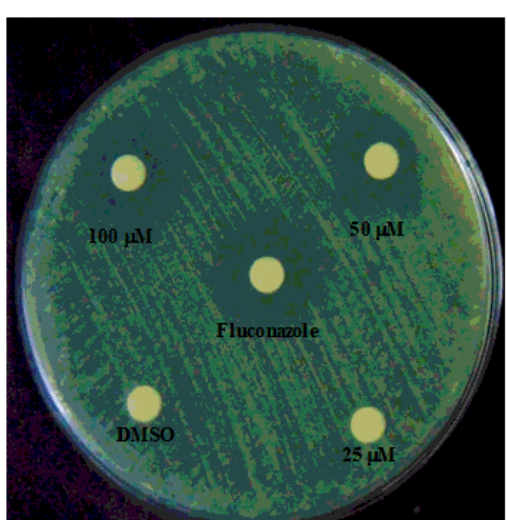

C

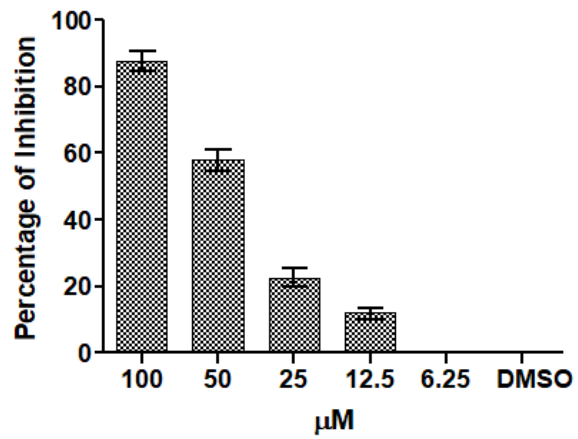

E

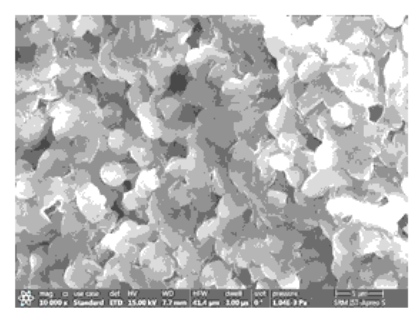

B

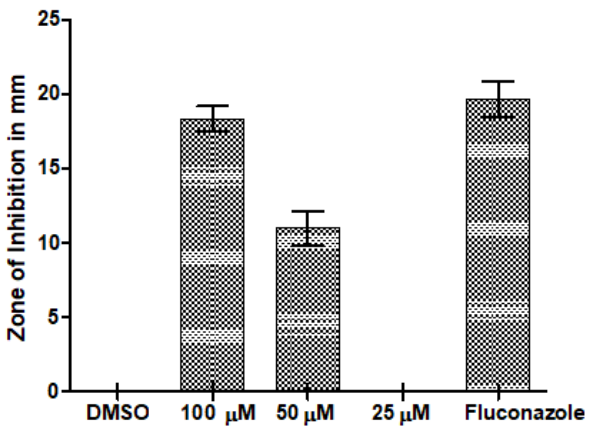

D

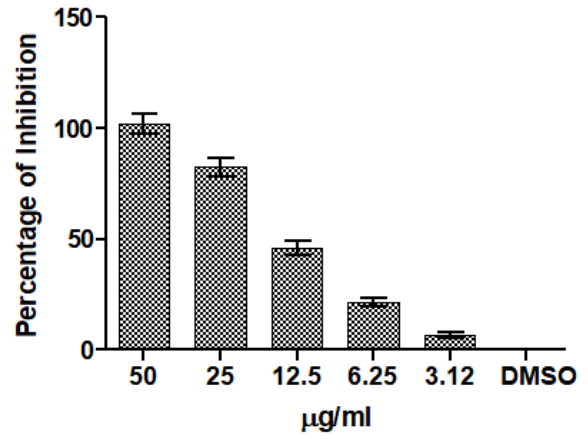

TDZ

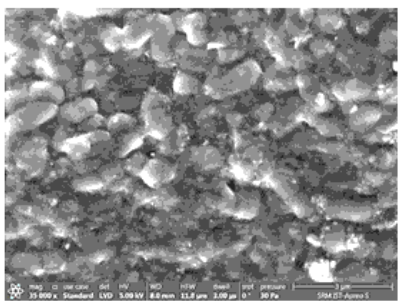

Fluconazole

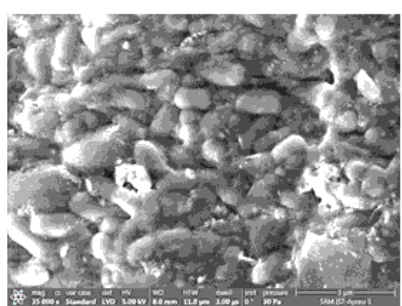

\section{Figure 2}

A. Disc-diffusion based antifungal susceptibility of C.albicans towards thidiazuron showing antifungal efficacy of thidiazuron (100, 50 and $25 \mu \mathrm{M})$ and fluconazole $(25 \mu \mathrm{g} / \mathrm{ml})$ as zone of growth inhibition; B. Thidiazuron induced dose dependent inhibition in growth of C.albicans. C. Microbroth dilution based planktonic minimal inhibitory concentration of thidiazuron (PMIC50 = $41.9 \mu \mathrm{M})$; D. Microbroth dilution based planktonic minimal inhibitory concentration of fluconazole (PMIC50 = $14.21 \mu \mathrm{g} / \mathrm{ml}$ ); Dose dependent inhibition in planktonic cell mass was notice in both thidiazuron and fluconazole treatment; E. Scanning electron microscope analyses of thidiazuron treated planktonic C.albicans. Overnight grown C.albicans cells were treated with PMIC50 of thidiazuron and samples were processed and documented using scanning electron microscope as described in material and methods section. SEM imaging shows intact C. albicans in control group, but in both thidiazuron and fuconazole treatment integrity of the cells membrane were disturbed. DMSO was used as the vehicle control and the values were expressed as the means \pm standard error of three replicates and results were considered significant for ${ }^{*} \mathrm{P} \leq 0.05 ;{ }^{* * P} \leq 0.01$. 


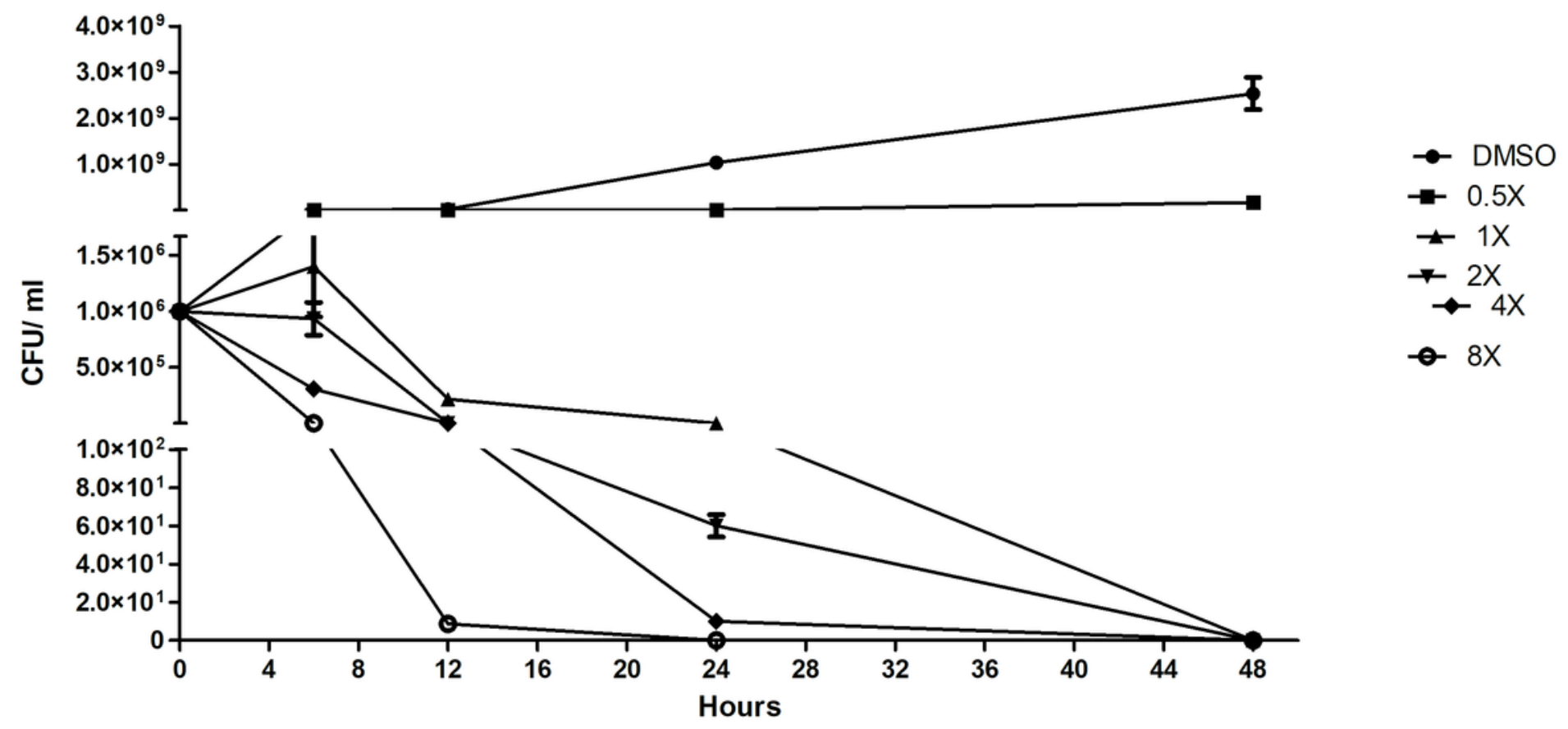

Figure 3

Time-killing curves of thidiazuron treated C. albicans. The initial yeast cell numbers were adjusted to $1 \mathrm{X} 106 \mathrm{CFU} / \mathrm{mL}$ and treated with thidiazuron at $0.5 \mathrm{X}, 1 \mathrm{X}, 2 \mathrm{X}, 4 \mathrm{X}$ and $8 \mathrm{X}$ PMIC50 concentrations. Samples were collected at 4 different durations $(6,12,24$ and 48 hours), plated on SDA plate and results were expressed as the means \pm standard error of three replicates. Viability of $C$. albicans was not affected by thidiazuron at $0.5 \mathrm{X}$ PMIC50, C. albicans viability was decreased in dose dependent manner when treated with higher PMIC. DMSO was used as the vehicle control and the values were expressed as the means \pm standard error of three replicates. 

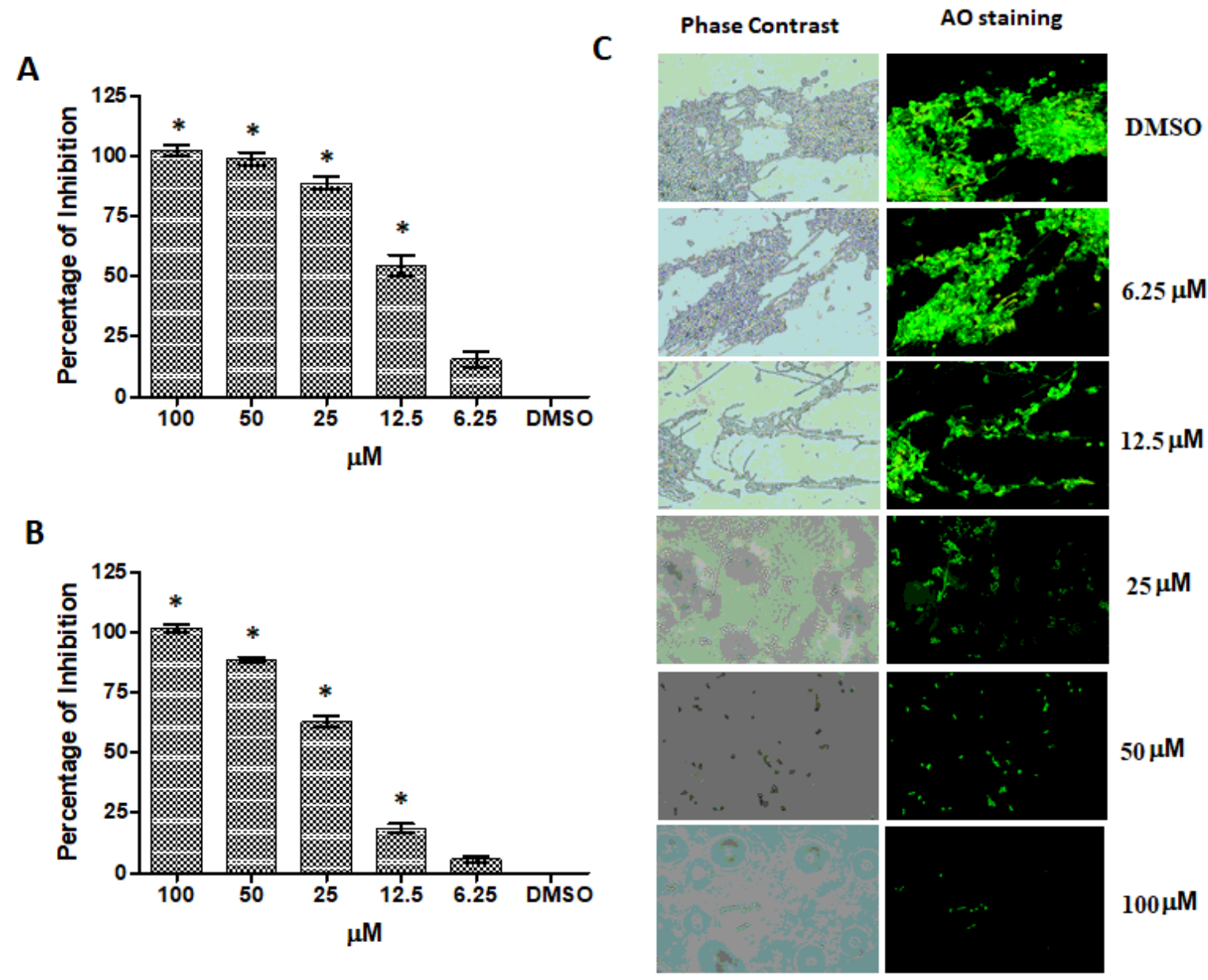

\section{Figure 4}

Effect of thidiazuron on C. albicans biofilm. A. Crystal violet staining based quantitative measurement of the C. albicans biofilm; B. XTT reduction assay based quantitative measurement of the $\mathrm{C}$. albicans biofilm; $\mathrm{C}$. Acridine orange staining of assessment of $\mathrm{C}$. albicans biofilm. Both quantitative measurement and microscopic observations revealed that thidiazuron has potency to inhibit $\mathrm{C}$. albicans biofilm from $6.25 \mu \mathrm{M}$ and that biofilm was completely inhibited by $100 \mu \mathrm{M}$ thidiazuron. DMSO was used as the vehicle control and the values were expressed as the means \pm standard error of three replicates. Results were considered significant for ${ }^{*} \mathrm{P} \leq 0.05 ;{ }^{* \star} \mathrm{P} \leq 0.01$. 


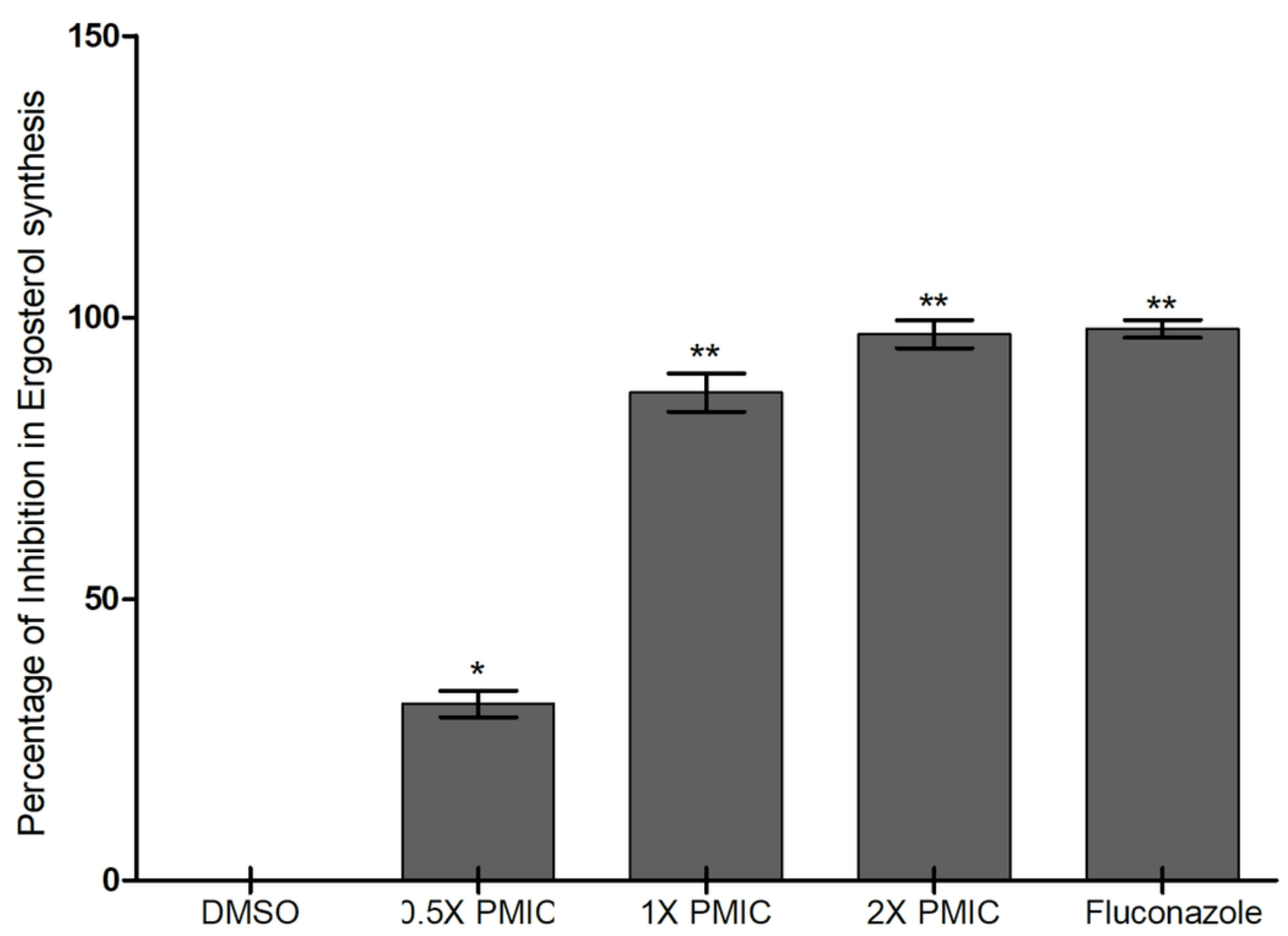

Figure 5

Effect of thidiazuron on ergosterol synthesis in C. albicans. The C. albicans cells $(1 \times 106 \mathrm{CFU} / \mathrm{ml})$ were treated with thidiazuron $(0.5 \mathrm{X}, 1 \mathrm{X}$ and 2X PMIC50) and the ergosterol content were quantified by scanning extracted sterol between 240 to $300 \mathrm{~nm}$. DMSO and fluconazole $(14.21 \mu \mathrm{g} / \mathrm{ml})$ treated cells were represented as negative and positive control, respectively. Values were expressed as the means \pm standard error of three replicates and results were considered significant for *P $\leq 0.05 ; * * P \leq 0.01$. 


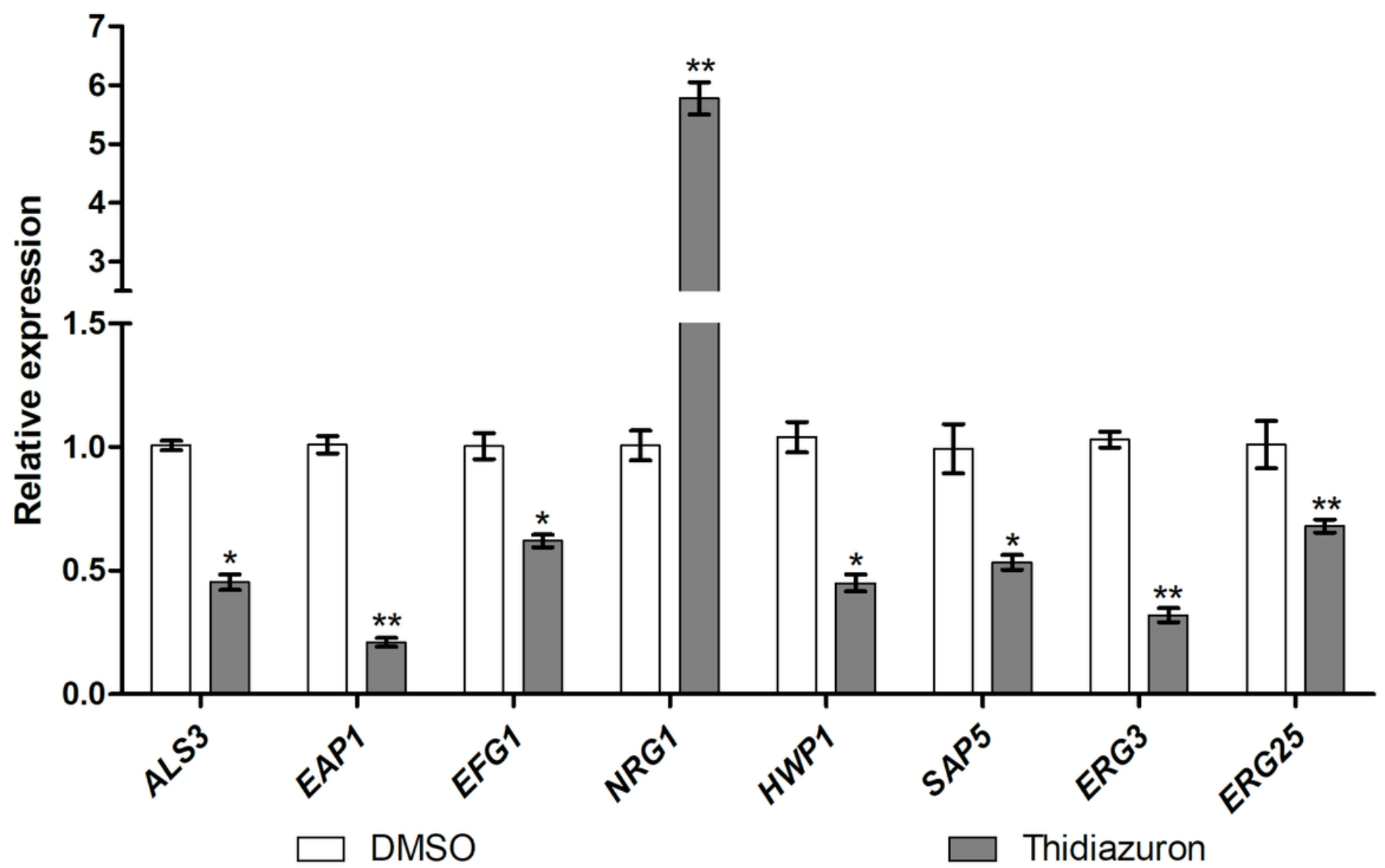

Figure 6

Quantitative real time PCR analysis of genes involved in C. albicans biofilm formation (ALS3 - Hyphal-specific Cell wall adhesin; EAP1 hyphae-specific cell wall adhesin protein; EFG1 - hyphae-specific gene activator; NRG1 - transcriptional repressor of hyphae-specific genes; HWP1 - hyphae-specific cell wall protein; SAP5 - secreted aspartyl proteases; ERG3 - C-5 sterol desaturase; ERG25 - methylsterol monooxygenase and ACT1 - actin related gene 1). RNA extraction and gene expression studies were conducted after $24 \mathrm{~h}$ incubation C. albicans under hyphae-inducing RPMI 1640 medium supplemented with $2 \%$ (w/v) glucose under DMSO and thidiazuron treatment. Gene expressions of all samples were normalized using ACT1 endogenous reference and relative gene expression of calculated based on DMSO treated C. albicans. Results were calculated using $2-\Delta \Delta \mathrm{Ct}$ method and expressed as mean relative expression \pm standard error of three replicates. Results were considered significant for ${ }^{*} \mathrm{P} \leq 0.05 ; \star \star P \leq 0.01$. 